\title{
Anaphylactic reaction at a pizzeria in a 13-year-old female patient
}

\author{
Alexander Herz · Matthias V. Kopp
}

Received: 6 September 2019 / Accepted: 24 October 2019 / Published online: 20 February 2020

(C) The Author(s) 2020

\section{Introduction}

According to the European Anaphylaxis Registry, anaphylactic reactions in children and adolescents are primarily triggered by foods and insect venoms. In terms of foods, the most frequent elicitors in children under 3 years are cow's milk and hen's egg, followed by peanut. The anaphylactic trigger was known in the majority $(95 \%)$ of reactions reported [1].

\section{Case report}

The case of a 13-year-old girl is reported here. The girl presented to the authors' pediatric emergency department with signs of a grade II anaphylactic reaction after eating a "Caprese" salad at an Italian restaurant with her family.

She reported that, within 1-2 min of taking the first bite, a tickling sensation in her throat developed and her tongue began to swell. She also experienced dyspnea and a sensation of tightness, as well as nausea without vomiting. Due to the close proximity of the pediatric emergency department, the girl could be rapidly transported by her parents in their private vehicle. She presented to the emergency department in an agitated state, accompanied by cold sweats and shivering. Her vital parameters were stable: blood pressure, $107 / 70 \mathrm{~mm} \mathrm{Hg}$, heart rate $94 / \mathrm{min}$, and $\mathrm{SpO}_{2}$ of $95 \%$. Her respiratory rate was slightly elevated at

\section{Dr. A. Herz ( $\square) \cdot$ M. V. Kopp}

Department of Pediatric and Adolescent Medicine, UKSH

Campus Lübeck, Ratzeburger Allee 160, 23538 Lübeck,

Germany

alexander.herz@uksh.de

\section{Dr. A. Herz}

Airway Research Center North (ARCN), German Center for Lung Research (Deutsches Zentrum für Lungenforschung, DZL), Lübeck, Germany 20/min. Further physical examination revealed normal pulmonary ascultation and skin findings.

An intravenous line was placed and, once vital parameters were overall stable, intravenous administration of prednisolone $(2 \mathrm{mg} / \mathrm{kg}=100 \mathrm{mg})$ and clemastine ( $2 \mathrm{mg}$ ) was initiated. There was no volume therapy or i.m. administration of adrenaline.

The symptoms improved in the further course and the patient was discharged home the next day following continuous vital sign monitoring. Prior to discharge anaphylaxis training was provided and emergency medication, including an adrenaline pen, was prescribed.

A reappraisal of the case yielded the following additional information: The young patient had no relevant pre-existing diseases and anthropometric data were normal (body weight $50 \mathrm{~kg}$, height $165 \mathrm{~cm}$, body mass index 18.4). She did not suffer from asthma and had no known previous food or inhalant allergies and no atopic dermatitis. She had experienced nonspecific mild urticaria with no clear trigger only twice in the preceding 4 years. In terms of family history, the mother suffered from allergic rhinoconjunctivitis. At the time of the anaphylactic event, she was neither ill nor had she undergone physical exertion that day.

According to the restaurant owner, the Caprese salad consumed shortly before the anaphylactic reaction had been prepared in the classic manner, comprising tomatoes, buffalo mozzarella, basil, balsamic vinegar, salt, and pepper. Apart from white bread, the patient had consumed no other food prior to the reaction. Buffalo mozzarella was the only ingredient in the salad that she had not knowingly consumed before. She ate the other foods regularly and always tolerated these well. The family had spent two family vacations in Italy. The parents of the patient had eaten buffalo mozzarella in the past. However, as far as the patient knew, she had not herself come into 
Table 1 Skin prick testing, performed in part as prick-toprick testing

Skin prick testing

\begin{tabular}{l|l|l|l|}
\hline Histamine & $4 \mathrm{~mm}$ & Olive oil & Negative \\
\hline Grasses & Negative & Buffalo mozzarella & $4 \mathrm{~mm}$ \\
\hline Birch & Negative & Milk & Negative \\
\hline $\begin{array}{l}\text { Dermatophagoides } \\
\text { pteronyssinus }\end{array}$ & Negative & Balsamic vinegar & Negative \\
\hline Cat & Negative & Yoghurt & Negative \\
\hline Alternaria alternata & Negative & - & - \\
\hline
\end{tabular}

previous contact with buffalo mozzarella, either when preparing food or eating at a restaurant.

The patient was discharged under the working assumption of "anaphylaxis following the consumption of buffalo mozzarella" and presented to the outpatient department again 4 weeks later for further evaluation.

Allergy testing performed on that occasion showed total immunoglobulin $\mathrm{G}$ (IgE) to be elevated to 141 $\mathrm{kU} / \mathrm{l}$. Specific IgE testing yielded negative levels to milk protein (f2), as well as to the allergen components nBos d4, nBos d5, nBos d8, and whey (f236). Specific IgE to alpha-Gal was also negative. The (differential) blood count was normal with no evidence of eosinophilia. Pulmonary function tests yielded no indication of an obstructive or restrictive respiratory disorder.

Skin prick testing, performed in part as prick-toprick testing, yielded an unequivocally positive result for buffalo mozzarella (identical to the product used in the restaurant with a skin index of 1, see Table 1).

Upon subsequent friction testing with buffalo mozzarella at the corner of the mouth, the patient reported that her "mouth swelled" and that she experienced dizziness after approximately $5 \mathrm{~min}$. The vital parameters measured were within the normal range (RR 104/60 mm Hg, HR 96/min, $\mathrm{SpO}_{2}$ 96\%).

Due to subjective symptom progression, an i.v. line was placed and clemastine $(2 \mathrm{mg})$ and prednisolone (100 mg) administered intravenously. After $6 \mathrm{~h}$ of continuous vital sign monitoring, the patient was discharged without symptoms.

\section{Discussion}

Buffalo mozzarella is produced from the milk of the water buffalo (Bubalus bubalis). In addition to buffalo milk, buffalo mozzarella also contains rennet and salt/brine. In many Asian countries such as India and Pakistan, buffalo milk represents the main supply of drinking milk. Both the protein and the fat content of water buffalo milk is higher compared to cow's milk [2]. There are numerous descriptions in the literature of cross-reactivity between the milk from various mammalian species in humans, in particular between cow, goat, sheep, and buffalo milk [3]. Homologies in amino acid composition and the phylogenetic rela- tionship between the species are believed to be causal $[3,4]$.

In contrast, isolated anaphylactic reactions to buffalo milk in the absence of cow's milk allergy are extremely rare. To the authors' knowledge, there are two case reports in adults in the literature. There have been no reports to date on buffalo milk allergy in children in the absence of cow's milk allergy.

The first case study was reported by Broekaert et al. in 2008. They reported on a 70-year-old man who exhibited generalized urticaria and angioedema, followed by dyspnea and loss of consciousness in the further course, after consuming buffalo mozzarella. The diagnostic work-up yielded normal skin prick test results and negative specific IgE to milk protein and its allergen components (alpha-lactalbumin, beta-lactalbumin, casein). A prick-to-prick test with buffalo mozzarella was positive [5].

A second case study reported on a 34-year-old woman who experienced an allergic reaction (angioedema) to the buffalo mozzarella topping on a pizza [6]. Specific IgE to protein, as well as to cow's, sheep's, and goat's milk, were negative. Here again, prick-to-prick testing was used to detect sensitization to buffalo mozzarella. The investigation conducted by Katz et al. demonstrated that pediatric patients who test positive for cow's milk in skin prick tests often also test positive in skin prick tests for buffalo milk. However, the clinical relevance of this observation is unclear, since no studies have been conducted as yet into the presence of a clinically relevant cross-allergy to buffalo milk in known cow's milk allergy [7].

The literature also describes isolated cases in which children with cow's milk allergy confirmed by specific IgE diagnostics tolerate buffalo milk without developing allergic symptoms [8]. The authors conjecture that relevant allergens in cow's milk are not found in buffalo milk and vice versa.

In summary, the patient discussed in this case report exhibited a grade II anaphylactic reaction after eating buffalo mozzarella for the first time. Specific IgE testing of milk protein components yielded normal findings. There was also no history of cow's milk allergy, nor was the patient sensitized to alpha-Gal. The patient ate mammalian meat, as well as the animal rennet usually found in Parmesan cheese, normally.

Prick-to-prick testing revealed sensitization (skin index 1.0; skin index = ratio of allergen-induced wheal to histamine-induced wheal in the skin prick test) to buffalo mozzarella. The manufacturers Phadia and Euroimmune do not offer commercially available specific IgE tests to buffalo milk.

Friction testing with buffalo mozzarella produced evidence of an immediate-type reaction involving dyspnea and dizziness within a few minutes. Immediatetype reactions in the context of food skin prick testing have been described [9]; however, it is not possible to reliably differentiate here from a psychological am- 
plification of symptoms. The friction test used here is not a standard procedure due to the unclear level of allergen exposure and, as such, is only rarely performed. Furthermore, a positive result can potentially be associated with contact urticaria, and gastrointestinal exposure may not result in corresponding allergic symptoms.

The family was offered the option of an inpatient oral food challenge, but declined due to fear of a repeat allergic reaction.

On the basis of the clear reaction in the skin prick test and the unequivocal history of an allergic reaction upon first exposure, the authors assumed the 13-yearold to be allergic to buffalo milk/buffalo mozzarella in the absence of cow's milk protein allergy. Sensitization may have occurred during a previous vacation in Italy. To the best of the authors' knowledge, this is the first description of buffalo milk allergy in the absence of cow's milk protein allergy in pediatrics.

Funding Open Access funding provided by Projekt DEAL.

Conflict of interest A. Herz and M.V. Kopp declare that they have no competing interests.

Open Access This article is licensed under a Creative Commons Attribution 4.0 International License, which permits use, sharing, adaptation, distribution and reproduction in any medium or format, as long as you give appropriate credit to the original author(s) and the source, provide a link to the Creative Commons licence, and indicate if changes were made. The images or other third party material in this article are included in the article's Creative Commons licence, unless indicated otherwise in a credit line to the material. If material is not included in the article's Creative Commons licence and your intended use is not permitted by statutory regulation or exceeds the permitted use, you will need to obtain permission directly from the copyright holder. To view a copy of this licence, visit http://creativecommons.org/licenses/by/4.0/.

\section{References}

1. Grabenhenrich L. Anaphylaxis in children and adolescents: TheEuropean Anaphylaxis Registry. JAllergy Clin Immunol. 2016;137:1128-37.

2. Zicarelli L. Buffalo milk: its properties, dairy yield and mozzarella production. Vet Res Commun. 2004;28:127-35.

3. Restani P. Cross-reactivity between milk proteins from different species. Clin Exp Allergy. 1999;29:997-1004.

4. Restani P. Cross-reactivity between mammalian proteins. Ann Allergy Asthma Immunol. 2002;6:11-5.

5. Broekaert S. Anaphylactic shock caused by buffalo's mozzarella cheese. Ann Allergy Asthma Immunol. 2008;101:105-76.

6. Bahal S. Second reported Case of Buffalo Milk Protein Allergy without Reactivity to Cow's Milk. J Allergy Immunol. 2017;1:5.

7. Katz Y. Cross-sensitization between milk proteins: reactivity to a "Kosher" Epitope? The Mosaic of. Autoimmunity. 2008;10:85-8.

8. Sheehan W. Tolerance to Water Buffalo Milk in a Child with Cow Milk Allergy. Ann Allergy Asthma Immunol. 2009;102:349.

9. Liccardi G. Systemic reactions from skin testing: literature review. J InvestigAllergol Clin Immunolo. 2006;16:75-8. 